\title{
HART AM WIND
}

Ein Unternehmen,

spezialisiert auf Antriebs-

stränge von Prüfständen,

bietet optimale Lösungen

zum Test von klassischen

und alternativen Antrieb-

en. Kontaktieren Sie uns!

\section{Liebe Leserin, lieber Leser,}

betritt ein neuer Kapitän die Brücke eines Flaggschiffs wie der ATZ/MTZ, dann erwarten ihn Neugier und viele Erwartungen. Die bisherigen Kapitäne, Wolfgang Siebenpfeiffer und Johannes Winterhagen, haben das Schiff ATZ/MTZ auf einen herausragenden Kurs gebracht und immer an der Spitze des Felds gehalten. Diesen Kurs gilt es zu festigen und weiter auszubauen. Hierbei darf die ATZ/MTZ den Entwicklungen nicht nur folgen, sondern muss immer von der führenden Position aus agieren. Es gilt nicht nur, neue Themen in das Portfolio aufzunehmen und neben den einheimischen Marken auf die Entwicklungen auf Seiten der Importeure zu fokussieren. Auch die Weiterentwicklung des elektronischen Auftritts unserer Medien ist eine der großen Herausforderungen der allernächsten Zukunft. Hieran wird die Redaktion gemeinsam mit Nachdruck arbeiten, um ATZ/MTZ sowie ATZelektronik und ATZproduktion auch weiterhin einen überragenden Auftritt zu ermöglichen.

Innovation ist dabei kein Selbstzweck, sondern ein Cocktail aus Qualität und Kontinuität mit einem guten Spritzer Begeisterung für Neues - garniert mit einer Scheibe Esprit. Augenmaß ist gefragt, denn eine Entwicklung kann nur dann zum Erfolg führen, wenn sie auf der Basis des bisher Erreichten erfolgt. Das Rezept muss also ausgewogen und geschmacklich raffiniert sein, damit es schmeckt und Hunger nach mehr macht. Sie merken, ich liebe es zu kochen, vor allem nach italienischer Art. Auf eine Zeitschrift übertragen heißt das: Das Produkt muss in erster Linie den Lesern schmecken und ihnen einen Mehrwert bieten. Dieses zu leisten hat die ATZ/MTZ bisher in herausragender Weise verstanden, und die neuen digitalen Inhalte auf „Springer für Professionals“ werden Ihnen schon bald ein deutliches Plus an Information und Aktualität servieren.
Die Automobil- und Motorentechnik samt Elektronik publizistisch zu begleiten, heißt ständig aufgeschlossen für Innovationen zu sein. Es gibt nicht viele Bereiche, die sich so dynamisch weiterentwickeln und verändern. Derzeit bestimmen vor allem die umwelt- und verkehrspolitischen Vorgaben die Entwicklungen in diesem Sektor. Darüber dürfen wir aber keinesfalls die Faszination vergessen, die vom Automobil und seiner Technik ausgeht. Nur mit einem „kräftigen Schuss Benzin im Blut“ können wir weiter hart am Wind, und damit schneller als die anderen, segeln.

Herzlichst, Ihr

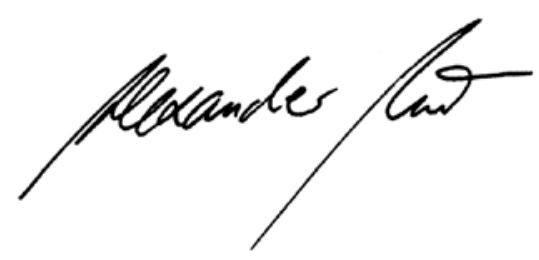

DR. ALEXANDER HEINTZEL, Chefredakteur Wiesbaden, 4. Juni 2012

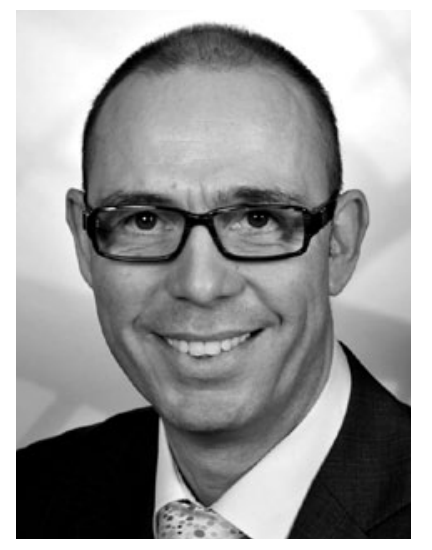

$\mathbf{t} 600$

Eine optimal abge-

stimmte hochelastische

Prüfstandswelle.

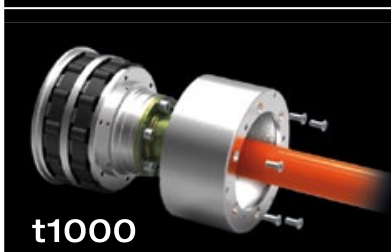

Die elastische Kupplung mit nichtlinearer Steifig-

keit und sehr hoher

Dämpfung. Besonders von Vorteil ist die einstellbare Steifigkeit.

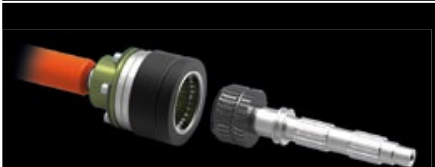

\section{tDock 800}

Ein manuelles Dock-

system entwickelt zum

Docken von Wellen auf

Prüfständen.

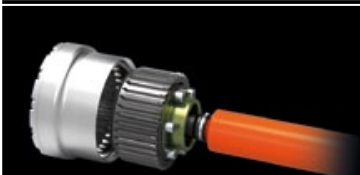

tDock 1500

Ein automatisches Dock-

system, entwickelt für

den Einsatz mit Paletten-

systemen.

\section{sectos}

technologies I tools I solutions

tectos gmbh

glacisstrasse 27

a-8010 graz | austria

$\mathrm{p}+43316228617$

f +4331622861715

office@tectos.at

www.tectos.at 